\title{
Intermammary Hidradenitis Suppurativa
}

\author{
Philippe Guillem ${ }^{a, b, c, d ~ V i r g i n i e ~ V l a e m i n c k-G u i l l e m ~}{ }^{e, f}$ \\ aDepartment of Surgery, Clinique du Val d'Ouest, Lyon, France; ${ }^{\text {b}}$ EuropeanHidradenitis Suppurativa Foundation, \\ Dessau, Germany; ${ }^{\mathrm{C}}$ RésoVerneuil, Paris, France; ${ }^{\mathrm{d}}$ Groupe de Recherche en Proctologie from the Société nationale \\ Française de ColoProctologie, Paris, France; eUniversité Claude Bernard Lyon 1, INSERM 1052, CNRS 5286, Centre \\ Léon Bérard, Centre de 9 Recherche en Cancérologie de Lyon, Lyon, France; 'Centre de Biologie Sud, Hôpital Lyon- \\ Sud, Hospices Civils de Lyon, Pierre-Bénite, France
}

Dear Editor,

We read with great interest the study published by João et al. [1] about the intermammary fold as a specific site affected by hidradenitis suppurativa (HS). We welcome the light shed on this location, which is probably not well known to clinicians and is rarely cited as such in the literature. In specific studies on localizations, it does not appear or is only included in the "breast localizations" [2]. Only one very recent study distinguishes it as an entity (called sternal form) among the other breast localizations [3].

As suggested by João's study, this specific presentation may be sustained by some anatomical and functional specificities, and the authors established a parallel with the pilonidal sinus disease (PSD). We agree that the configuration of the intermammary fold (a valley between the two hills represented by the breasts, just below the cervical concavity) is reminiscent of the configuration of the intergluteal fold (a valley between the two hills represented by the buttocks, just below the lumbar lordosis). Hair can consequently be trapped in this fold. Although part of the follicular occlusion tetrad, PSD has not been proved to be a true follicular occlusion; it is rather considered as the result of hair (and bacteria) penetration under the skin. The penetration of a hair into the skin of the gluteal fold is not only favored by a specific anatomical configuration but also by the mechanical constraints imposed by the sitting position and the shearing forces that walking induces between the buttocks. It remains to determine the forces (not very obvious) that would be at work in the intermammary fold. In other words, can the traction force exerted by (big) breasts and pectoral muscles on the intermammary fold be responsible for hair penetration as the shearing force exerted by (big) buttocks and gluteal muscles are?

The parallel between HS intermammary lesions and PSD is however clearly fueled by (1) the fact that they are both associated with a specific phenotype and (2) those phenotypes are similar $[1,4]$. In our personal series of 1,049 women followed in our center for HS since 2006 with complete clinical data, 89 presented with intermammary lesions (8.5\%), including only 6 with only intermammary HS localization. By comparing with other female patients, we also observed that patients with intermammary HS were younger at disease occurrence (17 \pm 6 vs. $21 \pm 8$ years, $p<0.001)$ and at first visit in the center $(27 \pm 9$ vs. $32 \pm 10$ years, $p<0.001)$. In our cohort, the first affected site was the intermammary fold in 24 women (2.3\%). As compared to the 1,025 women who started HS with another localization, those patients were again significantly younger: $17 \pm 6$ versus $21 \pm 8$ years, $p=0.005$. The mean BMI of the 89 patients with intermammary HS was significantly higher $\left(29 \pm 7\right.$ vs. $27 \pm 6 \mathrm{~kg} / \mathrm{m}^{2}, p<$ 0.001 ), as observed by João et al. [1]. Of interest, no correlation was observed between intermammary localization and neither family history of HS, smoking, or Hurley stage. Contrarily, we found that patients with intermammary HS were more frequently affected by PSD: 38 versus karger@karger.com

www.karger.com/sad
(C) 2022 S. Karger AG, Base
Correspondence to:

Philippe Guillem, docteurphguillem@outlook.com 
$28 \%(p=0.048)$, again arguing for common underlying mechanisms.

It is worthy to note that sternal localization (we cannot speak here of intermammary localization) can also be observed in men. In the 603 men of our HS cohort, 33 (5.5\%) had sternal lesions, a proportion significantly lower than the one observed in women $(p=0.024)$. Sternal skin was never the first HS localization in the men of our cohort. Whereas men with sternal HS were also younger at disease onset (19 \pm 6 vs. $22 \pm 8$ years, $p<0.001)$ and first visit in the center $(29 \pm 11$ vs. $33 \pm 11$ years, $p<0.001)$, their mean BMI was not different $\left(27 \pm 5 \mathrm{~kg} / \mathrm{m}^{2}\right.$ in both groups). Overall, the results obtained in the male population are also in favor of a specific role of anatomical configuration in the occurrence of intermammary/sternal HS.

\section{Conflict of Interest Statement}

P. Guillem received honoraria from AbbVie and Novartis as a consultant and provided lectures for AbbVie, Brothier, Cicaplus, Coloplast, Inresa, and Novartis. V. Vlaeminck-Guillem declares no conflict of interest.

\section{Funding Sources}

The authors have received no external funding.

\section{Author Contributions}

P.G. and V.V.-G.: design of the work, acquisition, analysis and interpretation of the data, and drafting of the work.

\section{References}

1 João AL, Cunha N, Cabete J. Intermammary hidradenitis suppurativa: considerations on a unique presentation. Skin Appendage Disord. 2021;7(4):318-21.

2 Benhadou F, Villani AP, Guillem P. Which factors determine affected sites in hidradeni- tis suppurativa? Dermatology. 2020;236(1): 15-20.

3 Andersen KR, Boer J, Jemec GE, Saunte DM. Mammary hidradenitis suppurativa lesions: a suggestion for phenotyping. Acta Dermatovenerol Croat. 2021;29(2):72-9.
4 Benhadou F, Van der Zee HH, Pascual JC, Rigopoulos D, Katoulis A, Liakou AI, et al. Pilonidal sinus disease: an intergluteal localization of hidradenitis suppurativa/acne inversa: a cross-sectional study among 2,465 patients. Br J Dermatol. 2019;181(6):1198-206. 